\title{
English Syllabics as Part of the British-American Voiceworks
}

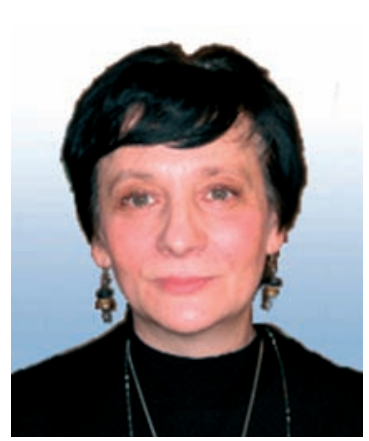

Svetlana Decheva

Since its emergence some 20 years ago syllabics, as a branch of philology which studies the functionalcommunicative potential of English syllabification, has sought at every level ways to optimize the process of language acquisition. The idea behind is that the English language with its outstanding syllabic capacities and readiness to lend itself to syllabifying processes of different kind is certainly in a class of its own. Practically every syllable, irrespective of its inherent characteristics, can be brought out to the utmost or, on the contrary, become phonetically degraded all at the speaker's own will. It is the syllable (not the sound or phoneme) that is most naturally isolated in the flow of speech. ${ }^{1}$

These pronouncements, which are no longer new nowadays, seem to acquire special significance in the so-called 'Global English' phonetic environment. The fact is that the mutual interference of different 'Englishes', and especially British and American diatopic variants, is becoming more and more interesting and involved at present. Moreover, it can even be used as a deliberate ploy to give a more general meaning or purport to the utterance. Suffice it to say that BBC newscasters, commentators and announcers whose professional qualifications are practically beyond any doubt, alongside standard pronunciation, have recently started to demonstrate a skilful variability of their speaking stereotypes, adapting their speech to the demands of effective communication on the new, 'global English' scale. ${ }^{2}$

This means that to get a deeper insight into the hidden mechanisms of modern English phonation, comprehensive (cognitive) approach to the dichotomy British English /American English is required. It should be based on a thorough study of English syllables as the basic units of articulation and perception of speech. It should be aimed at the intricacies of the English voice and those aspects of the two variants of English (British and American) which facilitate the process of communication at large. We should learn to process English speech in terms of the speaking-hearing syllable stereotypes of the two principal diatopic variants.

Very briefly and generally, what we are after in our British-American voiceworks is to become well equipped with the background knowledge of all those phonetic and (more specifically) syllabic particulars, which form the core of effective communication. Our final goal is to learn to be more selective so that we could choose and arrange different elements of British-American English consciously both with respect to the situation and the participants of speech intercourse. This may pave the way for the solution of the most intricate and so far unresolved problem of 'code-switching' both in 
oral and written forms of speech.

British-American voiceworks appear to be indispensable if what we are after is the "cognitive processing" of imaginative writing. By "cognitive processing" we mean the ability to understand, hear and voice a piece of verbal art, in strict accordance with the author's intention. This can by no means be achieved without special background knowledge of all the cultural-historical particulars of the text in question. Moreover, the goal can hardly be attainable unless we are keenly aware of British-American syllable stereotypes and those 'semiologically relevant' characteristics of one's speaking voice in British and American English against which everything that goes over and above the common run of things and makes for the expressive-emotional-evaluative overtones in these two diatopic variants is realized.

It should be noted here that reading American fiction, we have so far totally disregarded the most significant starting points of its adequate interpretation. We have not taken into account the 'semiologically relevant' characteristics of American speaking voice which, without exaggeration, underlie the prosodic polyphony of imaginative writing at large. In this paper, however, while concentrating on the peculiarities of American speaking voice, we do it against the background of the so-called RussianBritish-American trichotomy. In other words, we pay special attention to the principal discrepancies between the basic articulatory units of speech (or syllable stereotypes) of Russian (as our source language) and the two diatopic variants of English as our target language. Our task is to demonstrate how to reorient our perception and production habits with respect to the principal Russian-British-American trichotomy since being Russian, we are initially British English-oriented and are accustomed to assess whatever we come across in the English language solely with respect to British English phonetics, which we have studied so far.

Before we proceed with our discussion, a short metalinguistic digression concerning the phenomenon of British-American 'syllable stereotype' is necessary so that we could show how it helps us to read and understand different texts of verbal art reproducing them orally (or in our inner speech) and interpreting them adequately. We proceed from the premise that the syllable is a dynamic concept - it is the device for 'encoding' and 'decoding' linguistic messages. ${ }^{3}$ By dynamic word and syllable stereotype we mean the process of selection and combination of sounds typical of this or that language and used to compose words and messages.

Otherwise stated, verbal elements are formed in the shape of syllable and word stereotypes in accordance with which the standards of the language in question have already been established. This makes the process of human communication, i.e. the process of 'encoding' and 'decoding' messages, possible and operational and presupposes that there are certain tendencies of splitting the words into either checked (closed) or free (open) syllables. Hence we observe a completely different distribution of articulatory force in syllables and words, which could be described as 'intensity index'. ${ }^{4}$ It results in a peculiar kind of pronunciation, energetic pronunciation being typical of the English syllable on the whole.

Another point to be made clear here is that in British English the syllables are mostly 
checked, i.e. the consonant clings to the preceding vowel and cuts it at the peak of its formation. There are two crests of articulatory force in the British English syllable (at the beginning and at the end), and the syllable appears to be clear-cut and abrupt; it is more free and independent than its Russian counterpart. In American English, however, the situation is completely different. There is a general tendency towards losing the second peak, which makes for in an altogether different distribution of articulatory energy between vowels and consonants.

Otherwise stated, in British English, consonants are the 'fulcra' of pronunciation they are intensified and relied upon in the process of speech production, whereas in American English it is the vowel component, that acquires additional weight and is more important for syllable dynamics. The consonants, on the contrary, become weak and vague and may even be swallowed or replaced by glottal stops in the flow of speech. ${ }^{5}$

There is hardly any need to mention here that the basic principles of the American syllable stereotype have been formed under the influence of long-term muscular adjustments of the speaker's larynx and supra-laryngeal vocal tract. This is what accounts for the dynamics of American speech as opposed to that of British English, and it is the opposition of strong and weak off-glides and the general increase or decrease in the force of articulatory energy towards the end that really matters here.

Thus, two different modes of developing articulatory tension within the syllable underlie British and American speech. The whole effect of closed or checked syllables, which is typical of British English is not at all relevant in American English. Here the main tendency is to substitute laxity for tension and weakness for strength of articulation insofar as vowels and consonants are concerned. As for the borders of the syllables, they are blurred and indistinct, the general impression being of specific economy of articulatory effort.

We set so much store by this detailed analysis because what we are interested in is not 'voice' in its purely phonetic or terminological sense. Our task is to make clear that the question of British and American speaking voice is inextricably connected with syllables. In other words, what we are after is 'voice' in itsmore general sense, when it is used with reference to natural human speech at large. To be more exact, the word 'voice', as we use it, covers the most important aspects of speech production. ${ }^{6}$

The contrastive study of British and American speech proves to be rather illuminating in this respect. Our study shows that the most salient features of American English voice can be outlined only against the background of the American syllable stereotype and the Russian-British-American trichotomy. Let us consider them in greater detail.

There is every reason to believe that among all the basic parameters of voice, loudness usually comes first - it has an immediate effect on the interlocutor in the process of communication. At the same time loudness is not so easy to pinpoint unless it is measured in decibels and examined with the help of special machinery. Therefore, what we are after is not loudness as such, but the general effect of audibility and all those phonetic means which make speech intelligible, coherent and easy to follow.

The matter, however, is further complicated by the fact that Russian and English are 
characterized by different degrees of average loudness. A special research in the field has shown that the difference between Russian and British English in this respect is quite considerable. ${ }^{7}$ When analyzed through the prism of the opposition of the Russian language and British-American diatopic variants, American English seems to be in between its Russian and British counterparts. Acoustically it appears to be more audible than British English and less audible than Russian. This (purely impressionistic) view can be accounted for by the general tendency to dwell on the vocal element of the syllable, which provides the necessary conditions for 'speaking up' both in Russian and American English.

It is obvious, therefore, that for the British ear American English, let alone Russian, may sound too loud and even piercing sometimes. This does not mean, of course, that the British variant is less intelligible than the American one - all the syllables being more clear-cut and the strong syllable in particular being in charge of the clarity and lucidity of exposition, the general effect of audibility is created by completely different means, which are by no means to the detriment of comprehension.

Next come tempo and rhythm. As has been shown above, the American English syllable, more often than not, is made prominent by means of the quantitative component, which cannot but affect the tempo of American speech at large. Since all the syllables are prolonged, the tempo of American speech is slower than that of British English. According to the American school of elocution, the heart of American speech is "syllable length", one of the basic characteristic features of American rhythm, which deserves special attention.

The fact is that when learning to produce American speech, it is the technique of lengthening we should try and master. That is why rhythm in American English can hardly be described as the classical stress-timing of British English; nor is it the classical syllable-timed rhythm which is characteristic of French but it is somewhere in between. It is the 'borrowing rule' that makes for the effect of regularity here and one is to make sure that "when a long syllable is followed by a short one, the short one borrows time from it and makes it relatively short."

The next parameter is pitch-movement - is one of the most striking peculiarities of American English. It has been studied by very many linguists both in this country and abroad. ${ }^{9}$ For this research, however, the most important thing about it is the fact that our knowledge of the peculiarities of British English tones (the way they are realized within the intonational contour of British English) is hardly applicable to American English, where it is practically impossible for the voice either to fall to the bottom or to rise accidentally. The change in pitch is realized in steps, not in glides, which results in the typically 'American monotone', or the general 'levelling out' of all the syllables: both stressed and unstressed.

To be more exact, the stressed syllables are pronounced on one and the same level, whereas unstressed syllables either fall to a lower pitch or are on the same pitch as the preceding stressed syllables. There is very little pitch movement (if any at all): steady pitches prevail against the background of the general evening of stressed and unstressed syllables and a more or less equal distribution of energy throughout the utterance. 
Otherwise stated, mid level tones are primarily used in the flow of speech. As for the other two basic varieties of tones in the English language, i.e. the rising and the falling tones, their configuration in General American also undergoes considerable changes. In contrast with British English wide melodic curves, the tones of American English are narrowed and truncated. No wonder, typically British English pitches sound explosive and manneristic to Americans, who do not see the reason why abrupt changes in the melodic curve in alternating directions should be used so excessively. Thus, the 'serrated' profile of British English is generally opposed to the 'levelled out' pattern of American English. ${ }^{10}$

Last but by no means least comes timbre. We usually concentrate on the basic dichotomy of two timbres - Timbre I and Timbre II. Timbre I (or 'serious timbre') is practically devoid of any attitudinal evaluation on the part of the speaker. Loudness, tempo, pitch-movement and rhythm are kept within the bounds of intellective communication. There is nothing about them which stands over and above the common run of things or the semiologically relevant (unmarked) properties of the British and American speaking voice. Timbre II (or 'paradoxical timbre') is attitudinal throughout. It is the ability to modulate one's voice in terms of its basic parameters, which comes here to the fore. The thing is that being more a continuum than a divide, the established dichotomy of two timbres must again be analysed with respect to the principles of English syllabics, in which all the slightest prosodic modifications which take place in the flow of speech become quite transparent in the special treatment of separate syllables.

To put it in a nutshell, the task of our British-American voiceworks is twofold. On the one hand, what we certainly strive for is optimization of intellective communication in the new global English context. On the other hand, it is philological reading proper, that we are always after. It consists in gaining a much deeper insight into the reading of American fiction through the prism of English syllabics. This presupposes both background knowledge of 'semiologically relevant' British-American voice qualities conditioned by the work of the resonators, and ability to apprehend and make special use of those metasemiotically relevant timbral modifications which serve to convey different purports and can be perceived only against the more 'neutral' and stylistically unmarked syllable background.

This, however, is far from being sufficient, because the basic (or the semiologically relevant) parameters of what is generally described as the "speaking voice" of English acquire their functional value only when they are opposed to the meaningful absence of voice (or cessation of phonation), and the 'speechological' category of 'voice vs. absence of voice' is revealed fully.

It does not require a close examination to see that the cessation of phonation is ineluctably connected with the 'arresting' and 'releasing' phases of the neighbouring syllable; it is produced and perceived in speech only against the syllabic background. ${ }^{11}$ As the dynamics of British and American speech presupposes an altogether different mode of developing the articulatory tension within the syllable, the first thing is to concentrate on the peculiar off-glides of separate syllables, which in American English are not so clear-cut and self-contained as in British English. Everything depends on the way syllable 
sequences are treated, whether the syllabifying processes are made particularly pronounced or, on the contrary, they become blurred and indistinct due to the speaker's ability to cease (or interrupt) the pulmonic air stream by the accessory articulatory movements. In view of the habitual (typical of British and American speech communities) syllable stereotypes, the transition between the syllables are fast and abrupt in British English and rather slow and smooth in American English. In the former case the syllables are mostly clipped; in the latter they are drawled and lengthened.

It follows from what has just been said that when reading a text of verbal art, we can by no means confine ourselves to the semiologically relevant syllable stereotype of British or American English. We have to concentrate on "affective syllables", which goes far beyond the common run of things. ${ }^{12}$ The material of affective syllabics, therefore, appears to be extremely interesting and illustrative in this respect. It enables us to acquire the necessary knowledge of how different parameters of voice (that is loudness, tempo, pitch-movement, rhythm and timbre, as well as cessation of phonation or absence of voice) are used by the author to depict his characters and communicate his ideas and emotions more clearly.

Of special interest in this connection is "syllable-by-syllable" pronunciation, or "syllabic speech", when syllabifying processes are deliberately played upon by the author to convey his ideas to the readers in a peculiar and vivid way. Syllabification in this case has nothing to do with the purely graphical division of English words but it totally depends on the author's intention to use the graphical substance of the phenomenon in question. For this purpose spacing, italics, bold type, hyphenation, or combinations of some of these may be used.

Very often, however, syllabic speech is presented by means of hyphenation, whose signifying functions can acquire special values. When applied to syllabic speech, the hyphen can hardly be treated as a simple punctuation mark but is clearly in a class of its own. This is because the hyphen is not easily susceptible of immediate and traightforward prosodic interpretation, the way colons and commas, dashes and brackets are usually read. As Academician L. Scherba puts it: "The hyphen is hieroglyphic by nature". It requires special knowledge and proficiency to understand and interpret it adequately, let alone produce it by means of our speaking voice. ${ }^{13}$

It should be added here that since British-American syllable stereotypes are different, it is only natural that the basic tunes used to describe British English should also undergo considerable changes, when used with respect to American punctuation marks. Special research in the field has shown that the prosodic interpretation of the British system of stops against that of American English is far from being totally examined and expounded. Very much remains to be done if what we are after is reading them philologically, i.e. with all the phonetic-syllabic antecedents of the phenomenon in question being taken into account. ${ }^{14}$ In other words, to reproduce the hyphen by means of our speaking voice, we should be aware of the 'global vertical context' of the text or the speech event in question.

The concept of 'global vertical context' is indissolubly connected with linguistic erudition, which is too broad a term to be confined to background knowledge of the 
language in question. It also presupposes some special education of cultural-historical, social and geographical type, as well as the reader's philological intuition, which enables him to render all the author's emotions and ideas contained in this or that work of verbal art. ${ }^{15}$ This means that understanding fiction and reading texts philologically is impossible without the permanent and painstaking process of penetrating into the author's intention, gaining insight into the purport of the text and reading "between the lines", so to speak.

Our investigation shows that as distinct from British English, syllabic pronunciation is very widely spread in American speech in general, and American fiction in particular. In texts of verbal art it is not infrequently endowed with special semiotic value, signalling the author's hidden intention and serving as a sign of his "tongue-in-cheek" attitude to what he is saying. It usually indicates a switch into a peculiar kind of timbre, based on the incongruity of the prosody with the verbal context of the utterance.

O'Henry's manner of writing appears to be a goldmine in this respect as the study of syllabic pronunciation provides a clue as to what the more general ('paradoxical') timbre of his works is about. It usually presupposes a contradiction between the direct meaning of a word and its prosody. In other words, it implies enantiosemy, or the author's ironical (mocking) attitude to the events and characters described in the text.

This is one of O'Henry's favourite themes, which is based on contrasting appearance with reality and can be traced to L. Carrol's "through the looking glass" way of presenting things. In other words, syllable by syllable pronunciation in O'Henry's texts is subservient to the author's general artistic design. It would not be an exaggeration to say that it is as a powerful stylistic device, which helps the author to realize his artistic intention to the full.

To illustrate the point, let us turn to the following passage from O'Henry's story "Hearts and Crosses":

The horseman stumbled into the house. Two arms fell around his neck, and someone cried out in the voice of woman and queen alike: 'Webb-oh, Webb!'

'I was a skunk, 'said Webb Yeager.

'Hush, 'said Santa, 'did you see it?'

'I saw it, 'said Webb.

What they meant God knows; and you shall know, if you rightly read the primer of events.

'Be the cattle-queen, 'said Webb; 'and overlook it if you can. I was a mangy, sheepstealing coyote.'

'Hush!' said Santa again, laying her fingers upon his mouth. 'There's no queen here. Do you know who I am? I am Santa Yeager, First Lady of the Bedchamber. Come here.'

She dragged him from the gallery into the room to the right. There stood a cradle with an infant in it - a red, ribald, unintelligible, babbling, beautiful infant, sputtering at life in an unseemly manner.

'There's no queen on this ranch, 'said Santa again. 'Look at the king. He's got your eyes, Webb. Down on your knees and look at His Highness.' 
But jingling rowels sounded on the gallery, and Bud Turner stumbled there again with the same query that he had brought, lacking a few days, a year ago.

'Morning. Them beeves is just turned out on the trail. Shall I drive 'em to Barber's, or-

He saw Webb and stopped, open-mouthed.

'Ba-ba-ba-ba-ba-ba!'- shrieked the king in his cradle, beating the air with his fists.

'You hear your boss, Bud, 'said Webb Yeager, with a broad grin-just as he had said a year ago.

The whole passage is characterized by a peculiar blend of at least four voices: Mr.Yeager, his wife, their baby and the author. This means that the reading and understanding of the piece in question presupposes our ability to feel and interpret its peculiar prosodic polyphony. It totally depends on the interplay of both: the narrator's and his characters' voice parameters on the one hand, and the conscious cessation of phonation on the other, which is achieved and made operational only against the background of English syllabification.

Let us see how the author uses different syllables as the necessary background against which all kind of phonetic-morphological repetitions are realized. This is how O'Henry describes the infant:

There stood a cradle with an infant in it - a red, ribald, unintelligible, babbling, beautiful infant, sputtering at life in an unseemly manner.

This is a wonderful example of paronymic attraction, when the words with similar phonetic structures are brought together and played upon in the text for some special purposes, and thus become part of affective syllables. The whole effect is based on the repetition of the strong resonant $[\mathrm{r}]$ in "red-ribald", the weak plosive $[\mathrm{b}]$ and the consonant cluster [bl] in "babbling-beautiful" and "ribald-unintelligible", the strong sibilant [s] in "stood-sputtering" and the fricative [f] in "infant", "life" and "beautiful". In all these cases the syllables are characterized either by an abrupt change in the melodic curve or by an increase in duration and intensity of pronunciation, so that they become extra-strong and acquire additional weight. Interestingly enough, this description of a baby is based on different phonestemes with certain 'meaning' of their own if taken in isolation. In this text, however, they acquire special connotation against the syllabic background. Thus, the consonant cluster [sp], if taken out of this context, will usually be associated with something wet, smooth and soft; [b] - sounds like a sudden and strong blow; [r] - is associated with the idea of constant movement or instability.

Reading more deeply into the words of the author, however, we realize that what O'Henry is after is simply to show that it is the baby who forms the essence of matrimonial relations. It changes peoples' former attitudes, habits and ways of life and endows them with new significance, new rhythms and sounds typical of an adorable child. 
'Ba-ba-ba-ba-ba-ba!'-shrieked the king in his cradle, beating the air with his fists.

Baby talk is presented in this extract by similar, seemingly insignificant syllables coming one by one in a row and separated from each other by means of hyphens. There is nothing special about the phonetic structure of syllabic speech of this kind - it is more or less universal and consists of free (or 'open') syllables, with the plosive (or nasal) at the beginning and the front central vowel following it. These first sound sequences, which babies produce when they are learning to talk, are considered to be quite meaningless and in this sense they are not infrequently compared to elementary articulatory drills which people practise and repeat at their phonetic classes, imitating the correct pronunciation of the foreign language they are trying to master.

Baby talk, however, is very special because being rather unclear in articulatory terms, it usually reproduces the exact rhythmical pattern of 'adult' speech. In other words, syllables and rhythm naturally come first in speech acquisition. This psycholinguistic proposition proves very useful for our analysis. It forms part and parcel of the background knowledge of things which cognitive syllabics is after. Without it to process this text in syllabic terms would hardly be possible.

Thus, if we are fully aware of the basic, semiologically relevant properties of American speaking voice, we can easily surmise that the underlying rhythm of the syllable sequence "ba-ba-ba-ba-ba-ba" must be totally conditioned by the general principles of the "borrowing rule", which is the groundwork of the way American syllables function in the flow of speech. According to this rule, all the syllables must be extra strong, because each of them is followed by a pause indicated by means of hyphens. Otherwise stated, all the syllables are equally prominent, with the vocal or quantitative component being the key to the effect in question.

To this we have to add that whenever we use such a sequence, the most important thing is to understand what changes different syllables undergo (if any); what the result of their mutual influence or interdependence is. Clearly, in this case we have concurrent monobeats and mutual lengthening throughout. The general impression is that of the syllable by syllable beat, which is very much in the nature of "syllable-timing" or the socalled 'machine-gun' kind of rhythm, with all the syllables being evened out and spaced regularly.

This rhythmical pattern is prompted both by the graphical substance and our background knowledge of the basic peculiarities of American speaking voice with its own 'borderline' kind of rhythm, in a middle position between the classical stress-timing of British English and classical syllable-timing typical of the French language.

This, however, is only the first step in our analysis, which can by no means be sufficient if we wish to see what is there behind the conventional graphical representation and what the author is trying to convey. We should always bear in mind that it is the hieroglyphic nature of the hyphen that requires special treatment and consideration on our part. It indicates meaning rather than prosody and signals some special purport that the author is trying to get across. Therefore, what we have to concentrate on, first and foremost, is the metasemiotic character of English syllables: 
whether the mood which is created in our inner speech when we read the passage corresponds to the mood (or intention) of O'Henry, who seems to make rather extensive use of spacing and hyphenation, choosing the latter rather than any other stylistic device to convey his attitude and emotions.

'Syllabic speech' in O'Henry's story comes at the very end as if the author were playing on the reader's literary expectations, bringing us to a conclusion for which, apparently, we are totally unprepared. He makes special creative use of the disyllabic word "Barber", which is the name of the main character's business partner, by completely restructuring it and bringing it together with the seemingly insignificant syllables of the baby talk "ba-ba-ba". As a result, the latter acquires new significance encoded in the syllables arranged in an onomatopoeic sequence; this is no longer a babble of an innocent child, but the final word in the family quarrel, which almost ends in the main characters' separation. The author's instructive and slightly ironical voice is superimposed on the infant's shriek forming a kind of a new, 'paradoxical' timbre for the reader to hear and reproduce adequately. ${ }^{16}$

Taking into account the peculiarities of British and American English syllable stereotypes, rhythm and prosody, the hyphenated syllable sequence should be read in the following way: the overall loudness should be slightly diminished and the tempo slightly decreased so that the duration of all the syllables (or the time-span) should approximate the accentual pattern of the word 'Barber', with every second syllable in a disyllabic sequence being pronounced a little shorter than the previous syllable. The rhythm should be somewhere in a middle position between the monobeatic, syllable-timed pronunciation and the trochaic (or even dactylic) kind of enunciation, which is more typical of stress-timing. The pauses between the syllables (if at all) are obviously the shortest among all the meaningful manifestations of "cessation of phonation" which can take place in the flow of speech. They totally depend on the peculiar treatment of the releasing and the arresting phases of the hyphenated syllable sequence. Thus, the difference between the first and the second interstress intervals will be totally conditioned by the smooth transition in the former and the internal open juncture in the latter, where the vowel at the end of the syllable "ber" and the consonant $[b]$ at the beginning of "ba" appear as the arrest (or coda) of the preceding and the release (or onset) of the following syllable respectively.

It follows that it is impossible to read the passage philologically without the "global vertical context" of O'Henry's literary output at large. Our task is to learn to read between the lines, so to speak, and decipher the author's signs incorporated into the text for the careful reader to recognize and interpret appropriately.

To conclude: British - American voiceworks seem to be crucial for foreign philologists because they considerably broaden and deepen our understanding of the inner mechanisms of English phonation, paving the way to the most intricate problems of human communication both in oral and written forms of speech. 


\section{Notes and References:}

1. Here we see eye-to-eye with those scholars who consider syllables to be "the real units of speech" and insist on their 'Janus-faced' nature and their special place in linguistic hierarchy. See about it in greater detail in: Bolinger D. Aspects of Language. New York, 1975, p.58; Lass R. An Introduction to Basic Concepts. Cambridge, 1991, p.237; Decheva Svetlana. Cognitive Syllabics. // Folia Anglistica. Language Structure and Variation. Moscow, 1997, N 2, p.89-107.

2. See about it, for example, Decheva S.V., Anikhovskaya T.V. BBC English as Part of the Target-Oriented English Language Teaching. // Language Learning. Moscow, 2003, N 4, p.4 -22.

3. See about it, for example, Akhmanova O.S. Phonology, Morphonology, Morphology. Paris, 1971, p.135.

4. See Decheva S.V. Cognitive Syllabics. // Folia Anglistica. Moscow, 1997, N 2.

5. See about it, for example, Shakhbagova D.A.. Varieties of English Pronunciation, Moscow, 1982.

6. See Decheva S.V. The Bases of English Philology. Moscow, 2000.

7. See, for example, Davydov M.V., Yakovleva Y.V. Prosodic Images in English Speech. Moscow, 1999.

8. The rule in question is described in detail in Bolinger D. Two Kinds of Vowels. Two Kinds of Rhythm. Bloomington. Indiana: Indiana University Linguistics Club, 1981, p.17.

9. See, for example, Bolinger D. Intonation and Its Parts. California, 1986.

10. Hall R.S. Jr. Elgar and the Intonation of British English. // Intonation. 1972, p.282-285.

11. See Abercrombie D. Studies in Phonetics and Linguistics. London, 1965.

12. The term "affective syllabics" (афффективная силлаьика) can be traced back to the concept of "affective phonetics" - the third of the three phonetics academician L. Scherba clearly distinguished. See Щерьа Л.В. Фонетика французского языка. Москва, 1957.

13. Sее Щерьа Л.В. Языковая система и речевая деятельность. Л., 1974, с. 193-194.

14. Sеe Дечева Н.Г. Актуальные вопросы филологического чтения американской прозы. МГУ им. М.В. Ломоносова. М., 2005, 26с. // ИНИОН РАН N 59351.

15. See Akhmanova O.S., Zadornova V.Y. The Present State of Shakespeare Translation in the USSR. // Shakespeare Translation. Tokyo, 1975. Vol. 2, p. 150-160.

16. See Давыдов М.В. Звуковые парадоксы английского языка и их функциональная специфика. Москва, 1984. 


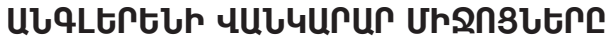

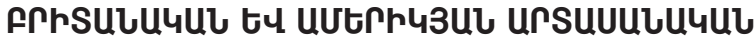 \\ surftru4utrntu}

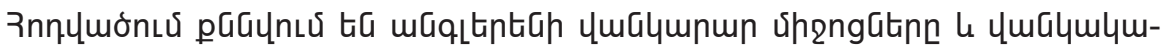

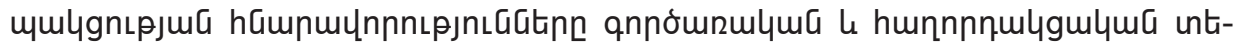

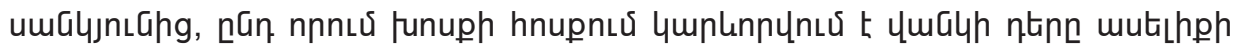

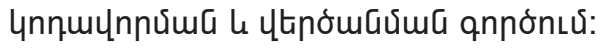

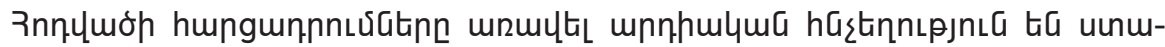

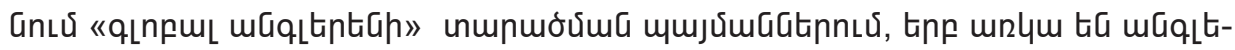

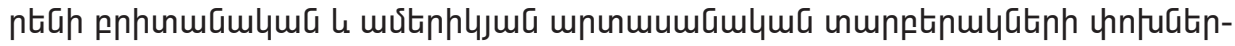

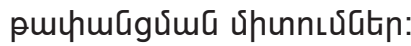

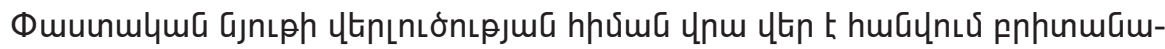

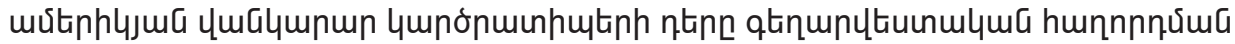

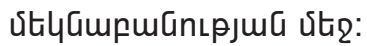

